\title{
The effect of collection substrate on electrospun ciprofloxacin-loaded poly(vinyl pyrrolidone) and ethyl cellulose nanofibers as potential wound dressing materials
}

5 Heyu Li ${ }^{\mathrm{a}, \mathrm{b}}$, Ziwei Zhang ${ }^{\mathrm{a}}$, V. Umayangana Godakanda ${ }^{\mathrm{a}, \mathrm{c}}$, Yu-Jing Chiu ${ }^{\mathrm{a}}$, Ukrit Angkawinitwong $^{\mathrm{a}}$, Karishma Patel ${ }^{\mathrm{a}}$, Paul G. Stapleton ${ }^{\mathrm{a}}$, Rohini M. de Silva ${ }^{\mathrm{c}}$, K. M. Nalin de Silva ${ }^{\mathrm{c}}$, Li-Min Zhu ${ }^{\mathrm{b}^{*}}$, Gareth R. Williams ${ }^{\mathrm{a}^{*}}$

a. UCL School of Pharmacy, University College London, 29-39 Brunswick Square, London, WC1N 1AX, UK

b. College of Chemistry, Chemical Engineering and Biotechnology, Donghua University, Shanghai, 201620, China

c. Department of Chemistry, University of Colombo, Colombo 00300, Sri Lanka

* Corresponding authors. Li-Min Zhu (Tel.: +86 21 67792659; Email: lzhu@dhu.edu.cn) and Gareth R. Williams (Tel.: +44 (0)207 7535868; Email: g.williams@ucl.ac.uk).

\footnotetext{
Abstract

In this work, nanofibers based on hydrophilic poly(vinylpyrrolidone) (PVP) and hydrophobic ethyl cellulose (EC) were generated via electrospinning. A model antibiotic, ciprofloxacin (CIF) was also incorporated into the fibers. Fibers were collected on both a foil substrate and a commercial gauze, the latter in the interests of developing a smart fabric. Electron microscopy images revealed that the fibers collected on both foil and fabric were homogeneous and cylindrical. Infrared spectroscopy, Xray diffraction and differential scanning calorimetry demonstrated that CIF was successfully loaded into the fibers and present in the amorphous physical form. In vitro drug release tests were conducted to simulate drug release from the formulations into a wound site, and as expected the hydrophilic fibers showed much faster release than
} 
their hydrophobic analogues. CIF was released through a combined mechanism of polymer erosion and drug diffusion, and the EC nanofibers displayed close to zeroorder release over three days. Fibroblast cells are able to grow and proliferate on the fibers. Finally, inhibition zone assays revealed that the growth of both Gram positive and Gram negative bacteria could be effectively inhibited as a result of the presence of CIF in the fibers. Electrospun nanofibers loaded with CIF thus have great potential in wound healing. Further, the fibers can be electrospun directly onto a gauze substrate to prepare a smart fabric.

Keywords: electrospinning, wound dressing, drug delivery, nanofibers

\section{Introduction}

The wound healing process is dynamic and complicated, and involves a number of processes including hemostasis, inflammation, proliferation and remolding. Would dressings are often used to cover the site of injury and accelerate the healing process. To do this, they should perform a range of functions, including: protecting the wound from infection, keeping the wound moist, absorbing fluids and exudates, accelerating the growth of new tissue, and being elastic, non-toxic, non-antigenic, and biocompatible [1]. To develop advanced dressing materials, various technologies have been explored, including the production of films, foams, hydrogels, hydrocolloids and hydrofibers [2-6].

Wound dressings with nanoscale features have a number of advantages [7], and many researchers have explored ways to generate such materials. Electrospinning is a costeffective, eco-friendly, and facile technique which can be applied to generate fibers with diameters on the nanoscale [8-10], and thus it can potentially be employed to prepare wound dressings. In addition to their high surface area-to-volume ratio and porosity, electrospun nanofibers collect as mats resembling the morphological structure of the extra-cellular matrix (ECM), which typically endows them with good 
biocompatibility [11]. According to the literature, electrospun wound dressings show promising hemostasis, absorption, and semi-permeability properties [1]. All these are crucial for effective wound dressing materials. Moreover, hundreds of therapeutic agents can easily be incorporated into the fibers, leading to the facile production of multifunctional dressings $[12,13]$. For example, Yang et al. developed silk fibroin nanofibers loaded with Manuka honey by electrospinning. The incorporation of the honey significantly improved the antimicrobial activity without any adverse effect on the biocompatibility of the fibers [14]. In other work, Ali et al. developed electrospun nanoparticle-in-nanofiber wound dressings that allowed for the controlled release of phenytoin [15]. These showed promising re-epithelization and healing performance during an in vivo study. However, there remains a lack of systematic understanding of drug release behavior from nanofibers into a wound site, and there is a need to perform release studies in more biorelevant conditions $[16,17]$. Further, it is likely to be necessary to deposit electrospun fibers onto other fabrics in order to obtain materials with appropriate mechanical properties for use as wound dressings. This area of research has attracted little attention.

5

Here, we prepared a series of fibers based on the biocompatible polymers polyvinylpyrrolidone (PVP) and ethyl cellulose (EC). PVP is a hydrophilic filamentforming polymer with a wide variety of applications in medicine, food, pharmacy, and cosmetics $[18,19]$. It is typically used to format fast-dissolving systems, and is on the FDA's generally regarded as safe list. EC is an inert water-insoluble hydrophobic polymer suitable for sustained release systems [20, 21]. Both polymers are electrospinnable and low cost. Electrospun nanofibers based on these polymers have shown promise for drug delivery and wound healing in previous work [22-26].

Ciprofloxacin (CIF), a fluoroquinolone antibiotic, was incorporated into the fibers to provide antibacterial properties. CIF-loaded fibers have been reported on a number of occasions. For instance, He et al. used a direct-writing melt electrospinning method to generate poly( $\varepsilon$-caprolactone)/poly(ethylene glycol) fibers incorporating CIF [27]. 
Variation of the ratio of the two polymers permitted the drug release profile to be tuned. Other researchers have prepared electrospun fibers loaded with CIF from alphaglycolic acid) [30]. Systems responsive to temperature [31] and acoustic stimuli [32] have also been reported.

In this work, we explored whether it was possible to use electrospinning to functionalize an existing fabric dressing. Hence, fibers were collected both on a conducting foil (as is standard in electrospinning experiments) and on a gauze (to prepare smart fabrics). Detailed characterization, dissolution and antibacterial assays were conducted. This paper comprises, to the best of our knowledge, the first systematic side-by-side study of fibers collected on gauze and foil and provides new insight into the potential use of electrospun materials in wound healing.

\section{Experimental}

\section{Materials}

Poly(vinylpyrrolidone) (PVP, MW 40,000 Da), ethyl cellulose (EC, 48\% ethoxy, 4cp), anhydrous ethanol, 1,1,1,3,3,3-hexafluoro-2-propanol (HFIP, $\geq 99.5 \%$ ), and ciprofloxacin (CIF, $\geq 98 \%$ ) were supplied by Sigma-Aldrich Ltd. Phosphate buffered saline (PBS, $\mathrm{pH}=7.4$ ) tablets were supplied by VWR Life Sciences. All other chemicals were analytical grade, and all water used was deionized before use. DMEMGlutaMAX ${ }^{\mathrm{TM}}$ high glucose, penicillin-streptomycin solution, fetal bovine serum and a LIVE/DEAD ${ }^{\circledR}$ cell vitality assay kit were procured from ThermoScientific.

\section{Preparation of electrospinning solutions}

PVP or EC powders were dissolved in HFIP under magnetic stirring overnight at room temperature to yield homogenous solutions. The polymer concentration was $13 \% \mathrm{w} / \mathrm{v}$. CIF was added at two different concentrations, $5 \%$ and $15 \% \mathrm{w} / \mathrm{w}$ (with respect to the polymer concentration). These concentrations were selected following a series of 
optimization steps and based on our previous experience [29]. Full details of the systems prepared are listed in Table 1.

120 Table 1. Details of the electrospinning experiments reported in this work. All solutions were prepared in HFIP.

\begin{tabular}{ccccc}
\hline Sample & Solution contents & $\begin{array}{c}\text { Polymer conc } \\
(\% \mathbf{w} / \mathbf{v})\end{array}$ & $\begin{array}{c}\text { Drug conc } \\
(\boldsymbol{\%} \mathbf{w} / \mathbf{w})^{\mathbf{a}}\end{array}$ & Collector \\
\hline S1 & PVP & $13 \%$ & --- & Foil \\
S2 & PVP/CIF & $13 \%$ & $5 \%$ & Foil \\
S2G & PVP/CIF & $13 \%$ & $5 \%$ & Gauze \\
S3 & PVP/CIF & $13 \%$ & $15 \%$ & Foil \\
S3G & PVP/CIF & $13 \%$ & $15 \%$ & Gauze \\
S4 & EC & $13 \%$ & --- & Foil \\
S5 & EC/CIF & $13 \%$ & $5 \%$ & Foil \\
S5G & EC/CIF & $13 \%$ & $5 \%$ & Gauze \\
S6 & EC/CIF & $13 \%$ & $15 \%$ & Foil \\
S6G & EC/CIF & $13 \%$ & $15 \%$ & Gauze \\
\hline
\end{tabular}

${ }^{a}$ With respect to the polymer concentration.

\section{Electrospinning}

125 Solutions were loaded into a $5 \mathrm{~mL}$ plastic syringe (Terumo) fitted with a stainless-steel flat-tipped needle (20G, $0.61 \mathrm{~mm}$ inner diameter, Nordson EFD), and the syringe mounted on a syringe pump (KDS100, KD Scientific). A flow rate of $0.8 \mathrm{~mL} / \mathrm{h}$ was used during electrospinning. A high voltage power supply (FuG Elektronik HCP3535000 ) was used to apply a positive voltage of $16 \mathrm{kV}$ between the needle and a

130 grounded collector (a flat piece of aluminum foil of $10 \times 10 \mathrm{~cm}$ in size). Samples were also collected with a sample of sterile commercial cotton gauze (Safe House Pvt Ltd) covering the foil. The distance between the needle tip and the grounded collector was set at $20 \mathrm{~cm}$. The relative humidity was ca. $40 \%$, and the temperature $25{ }^{\circ} \mathrm{C}$. After electrospinning for $6 \mathrm{~h}$, the products were stored in a desiccator at room temperature for $24 \mathrm{~h}$, to remove any residual solvent.

Fiber characterization 
The fiber morphology was studied by scanning electron microscopy (SEM; Quanta $200 \mathrm{~F}$ instrument, FEI) at a voltage of $5 \mathrm{kV}$. Samples were cut from the fiber mats, and sputter coated with gold for $60 \mathrm{~s}$ under argon to render them electrically conductive. The mean diameter of the fibers in each sample was then determined using the ImageJ software (National Institutes of Health) to make measurements at more than 100 points in each SEM image.

X-ray diffraction (XRD) data were acquired on a MiniFlex 600 diffractometer (Rigaku) supplied with $\mathrm{Cu} \mathrm{K \alpha}$ radiation $(\lambda=1.5418 \AA$ ) at a voltage of $40 \mathrm{kV}$ and current of 15 $\mathrm{mA}$. Patterns were collected over the $2 \theta$ range $3-35^{\circ}$ at a scan speed of $5^{\circ} \mathrm{min}^{-1}$.

Infrared (IR) spectroscopy was performed using a Spectrum 100 instrument

(PerkinElmer). Samples were studied over the range of 4000 to $650 \mathrm{~cm}^{-1}$, with the spectral resolution set at $1 \mathrm{~cm}^{-1}$. Four scans for each sample were recorded.

Differential scanning calorimetry (DSC) studies were conducted using a Q2000 calorimeter (TA instruments). Non-hermetically sealed samples in aluminium pans (Tzero premium pan/lid, TA instruments) were heated from 40 to $300{ }^{\circ} \mathrm{C}$ at a rate of $10{ }^{\circ} \mathrm{C} \mathrm{min}-1$, under a nitrogen flow of $50 \mathrm{~mL} \mathrm{~min}^{-1}$. Data were analyzed using the TA Instruments Universal Analysis software.

\section{In vitro drug release}

Dissolution experiments were carried out with a home-made dissolution device designed to simulate the drug release from dressings to wounds. This type of set-up has been found to give similar release profiles to a Franz cell experiment [33], but is much simpler to implement. First, fiber samples $(50 \mathrm{mg})$ were cut from each fiber mat, folded and enclosed in a dialysis bag. The bags were sealed and mounted on home-made HDPE (high density polyethylene) clips (Figure 1(a)). The clips were then immersed in $60 \mathrm{~mL}$ of PBS buffer at $\mathrm{pH} 7.4$, and stirred at $110 \mathrm{rpm}$ at $37{ }^{\circ} \mathrm{C}$. The dissolution device is 
depicted in Figure 1(b). This arrangement results in essentially unidirectional drug release, as would be the case for a wound. At predetermined time points, $1 \mathrm{~mL}$ of the test medium was withdrawn and an equal amount of fresh buffer (pre-heated to $37^{\circ} \mathrm{C}$ ) was added. CIF release was determined by UV spectroscopy (Cary 100 instrument) at $271 \mathrm{~nm}$. All release studies were performed in triplicate, and the results are given as mean \pm S.D.

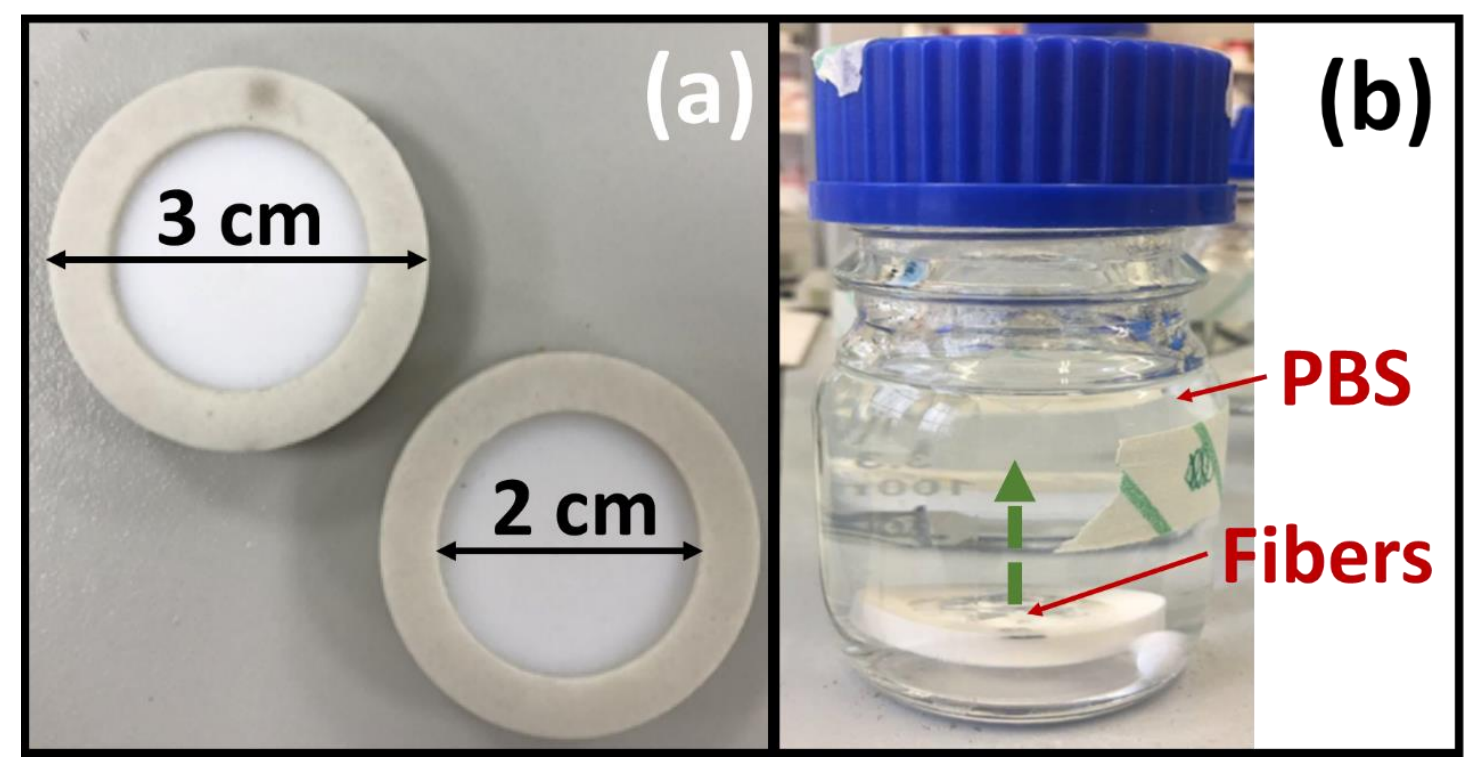

Figure 1. The dissolution apparatus, showing (a) the home-made HDPE clips and (b) the dissolution experiment. The arrow in (b) indicates the direction of drug release.

\section{Cell viability}

The cell viability of human dermal fibroblast (HDF) cells at passage 15-20 was explored after $24 \mathrm{~h}$ of incubation with the PVP and EC fiber formulations. PVP/CIF and EC/CIF fibers were prepared as detailed above, but with round $1 \mathrm{~cm}$ cover slips placed on the foil collector. The cover slips were sterilized using UV radiation for $1 \mathrm{~h}$, and placed into the wells of a 24-well plate. HDF suspensions were prepared at $5 \times 10^{4}$ cells/mL in complete DMEM GlutaMAX ${ }^{\mathrm{TM}}$ (supplemented with $1 \% \mathrm{v} / \mathrm{v}$ penicillinstreptomycin and $10 \% \mathrm{v} / \mathrm{v}$ fetal bovine serum), and $1 \mathrm{~mL}$ of the cell suspension placed in each well of the plate. The plate was then incubated for $24 \mathrm{~h}$ at $37^{\circ} \mathrm{C}$ and $5 \% \mathrm{CO}_{2}$.

Cell viability was assessed using the LIVE/DEAD ${ }^{\circledR}$ cell vitality assay kit (with $\mathrm{C}_{12}$ - 
Resazurin and SYTOX ${ }^{\circledR}$ Green Stain) after incubation. The cell supernatant was first removed, and the cells then treated with diluted $\mathrm{C}_{12}$-Resazurin $(12.5 \mathrm{nM})$ and SYTOX ${ }^{\circledR}$ Green $(100 \mathrm{nM})$ in PBS $(100 \mu \mathrm{L})$ before being incubated at $37^{\circ} \mathrm{C}$ and $5 \% \mathrm{CO}_{2}$ for 15 min. Thereafter, cold PBS $(400 \mu \mathrm{L})$ was added to each well of the plate and the fluorescence at $563 \mathrm{~nm}$ excitation / $587 \mathrm{~nm}$ emission was monitored using a Tecan Infinite M200 plate reader. Cell viability is expressed as a percentage where untreated cells are taken to have $100 \%$ viability. Data are presented as mean \pm S.D. $(n=3)$. In addition, the cell morphology was imaged using an EVOS XL inverted digital microscope.

\section{Antibacterial activity}

The antibacterial activities of the nanofibers were studied using the disc diffusion method of the US Clinical and Laboratory Standards Institute [34]. $10^{5}$ colony forming units (CFUs) of E. coli (Gram-negative; ATCC25922) and S. aureus (Gram-positive; ATCC 27853) were selected as representative microorganisms, and cultured on Luria broth and nutrient broth agar plates, respectively. $1.8 \mathrm{~cm}$ diameter discs were cut from each fiber mat and sterilized with $75 \%$ alcohol steam for 24 h. $100 \mu \mathrm{L}$ of each microorganism solution was cultured on an agar plate in a petri dish, and then a fiber disc was placed on the surface of the plate. All the dishes were incubated at $37^{\circ} \mathrm{C}$. Inhibition zones were measured after incubation for $24 \mathrm{~h}$. Three independent experiments were performed, and the results are given as mean \pm S.D.

\section{Results and discussion}

\section{Initial optimization}

All the solutions S1 to S6 can be successfully electrospun. The flow rate, voltage applied, and nature of the polymer concentrations were initially varied to determine the most appropriate conditions to use for spinning. These were found to be as detailed in the Experimental section. The feasibility of collecting fibers onto a commercial gauze 
was also assessed. Images of the gauze after electrospinning are given in the Supplementary Information, Figure S1. It is clear that an even coverage of fibers on the gauze can be obtained, and the fibers obtained appear to be linear and regular in their morphologies.

\section{Fiber morphology}

The morphology of the fibers collected on foil can be seen in Figure 2. In all cases, the fibers are homogeneous and smooth. The PVP samples (S1-S3) show some evidence for merged fibers, which could result from the presence of absorbed water (PVP is hydroscopic). A small number of beads can be seen in the CIF-loaded fibers (S2, S3, S5 and S6). The average diameters of the fibers are summarized in Table $\mathbf{2}$. They have mean diameters ranging from 300-900 $\mathrm{nm}$. The neat PVP fibers have the highest diameter $(832 \pm 241 \mathrm{~nm})$. With the addition of CIF, the mean diameters decreased to $743 \pm 182 \mathrm{~nm}$ for S2 and $541 \pm 162 \mathrm{~nm}$ for S3. The EC fibers (S4-S6) show a similar trend. The reduction in diameter may result from an increase in the solution conductivity following the addition of CIF; this is known to facilitate elongation of the polymer jet and to generate narrower fibers [34].

In addition, the CIF-loaded fibers were also electrospun onto a gauze substrate. The resultant materials are denoted S2G, S3G, S5G and S6G. The SEM images of these are given in the Supplementary Information (Figure S2). Again, clear fibers can be seen to have formed, albeit with more curvature. The mean diameters (Table 2) are essentially identical to the formulations collected on foil. The use of a gauze substrate thus does not have any obvious effects on the morphology or size of the fibers. Therefore, CIFloaded PVP or EC fibers can be collected onto fabric for direct application to a wound. 


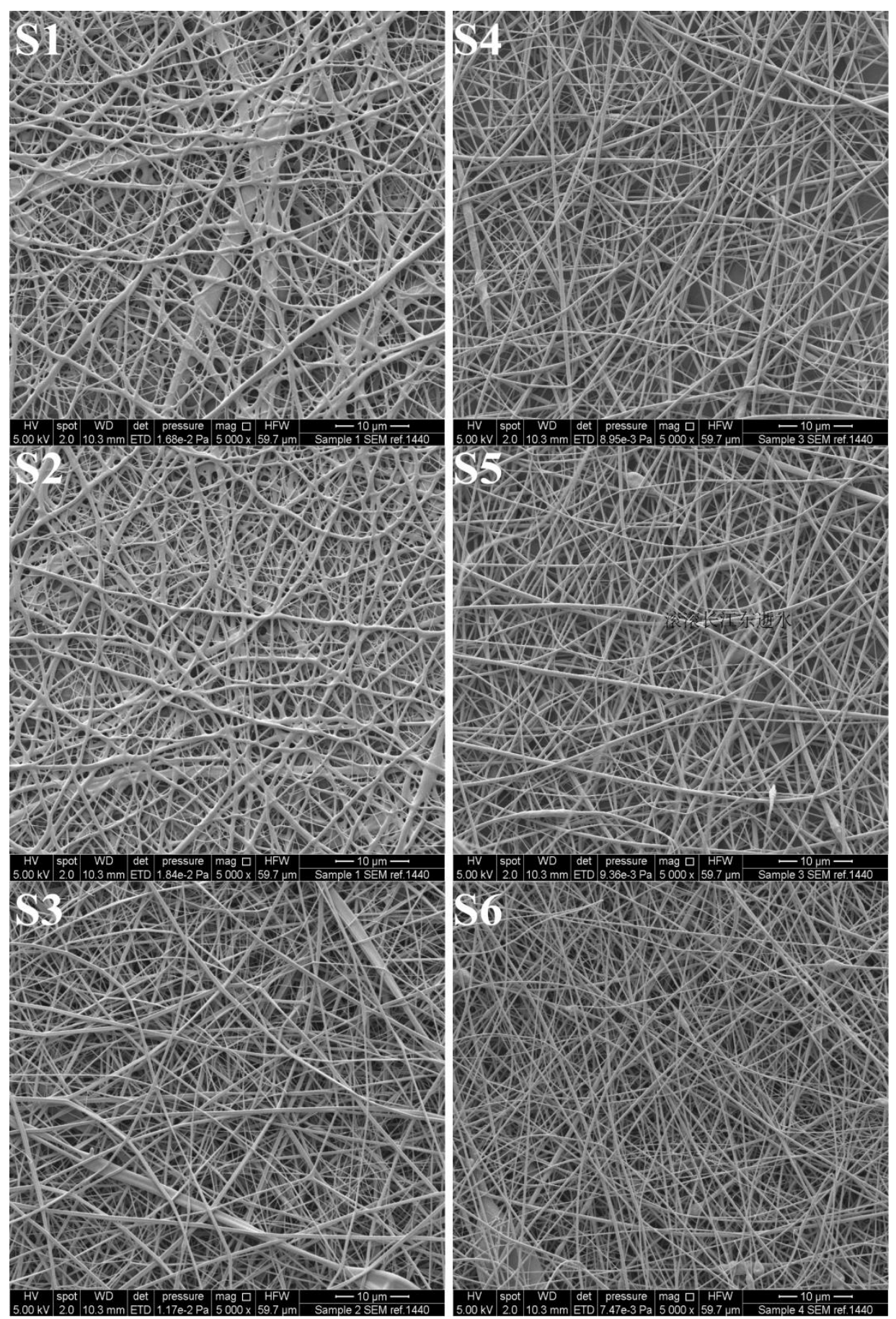

Figure 2. SEM images of the fibers collected on foil. The scale bar represents $10 \mu \mathrm{m}$. 
Table 2. The mean diameters of the fiber samples. Values are given as mean \pm S.D. from at least 100 measurements.

\begin{tabular}{cccc}
\hline \multicolumn{2}{c}{ Foil collector } & \multicolumn{2}{c}{ Gauze collector } \\
Sample & Diameter (nm) & Sample & Diameter (nm) \\
\hline S1 & $832 \pm 241$ & -- & -- \\
S2 & $743 \pm 182$ & S2G & $720 \pm 127$ \\
S3 & $541 \pm 162$ & S3G & $550 \pm 134$ \\
S4 & $597 \pm 214$ & -- & - \\
S5 & $435 \pm 137$ & S5G & $439 \pm 159$ \\
S6 & $368 \pm 108$ & S6G & $395 \pm 154$ \\
\hline
\end{tabular}

\section{$X$-ray diffraction}

XRD patterns of pure CIF and all the fiber samples collected on foil (S1-S6) are shown in Figure 3. CIF displays a number of characteristic Bragg reflections in its diffraction pattern, demonstrating the raw drug to be crystalline. In contrast, the S1 and S4 fibers (PVP and EC alone, respectively) display no Bragg reflections in their patterns, but rather these comprise broad haloes. Similarly, all the drug-loaded fiber formulations have patterns exhibiting broad haloes. This demonstrates them to be amorphous materials, as is typically found with electrospun materials owing to the very rapid nature of the drying process [35-36]. 


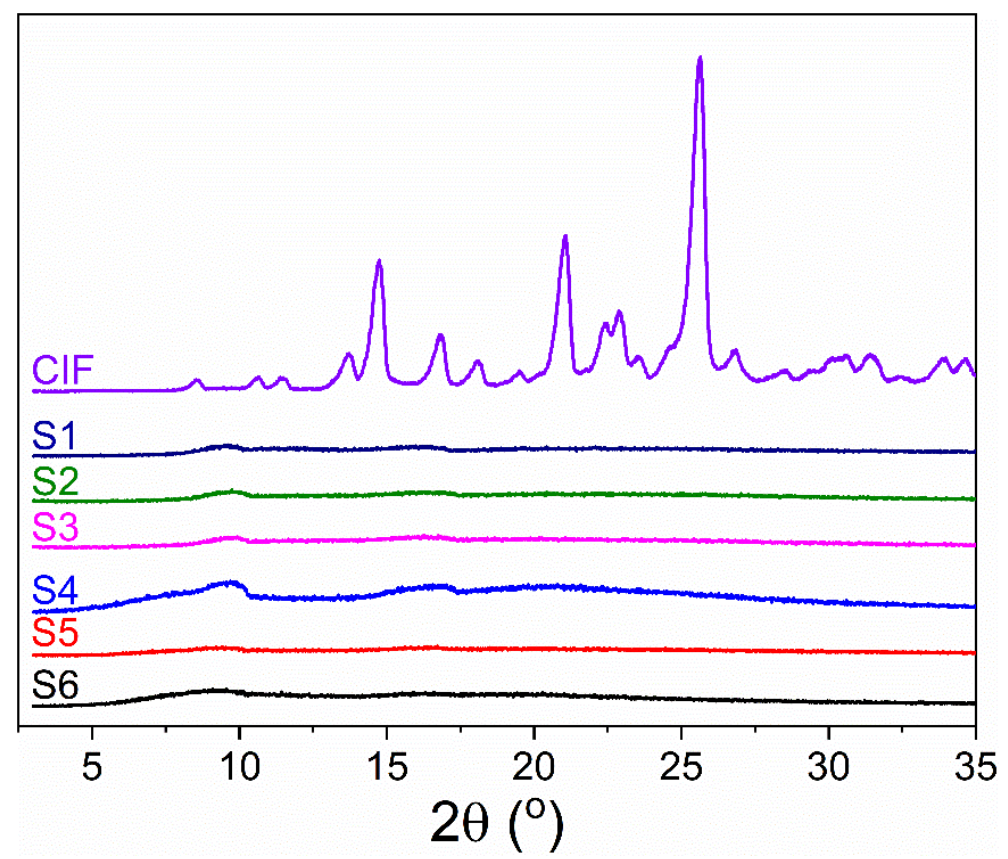

Figure 3. XRD patterns of the fibers collected on foil and pure CIF.

\section{Differential scanning calorimetry}

DSC thermograms are presented in Figure 4. CIF exhibits a sharp endothermic melting peak at $276{ }^{\circ} \mathrm{C}$, confirming its crystalline nature [37]. However, no fusion events are visible in the DSC thermograms for any of the fiber samples, suggesting that CIF exists in the amorphous state after electrospinning. This confirms the XRD findings, and it can hence be concluded that the fibers comprise amorphous solid dispersions. Similar results have been reported in the literature [38, 39]. Solvent evaporation during electrospinning is very rapid, which usually means that there is insufficient time for the drug molecules to order themselves into a regular crystalline arrangement during drying. The random arrangement of molecules in the solution phase is carried through into the solid product, leading to the drug molecules forming a solid solution in the polymer matrix $[40,41]$. There are no broad endotherms visible in the DSC traces of any of the fiber formulations, confirming the complete evaporation of HFIP during the spinning and storage processes. 


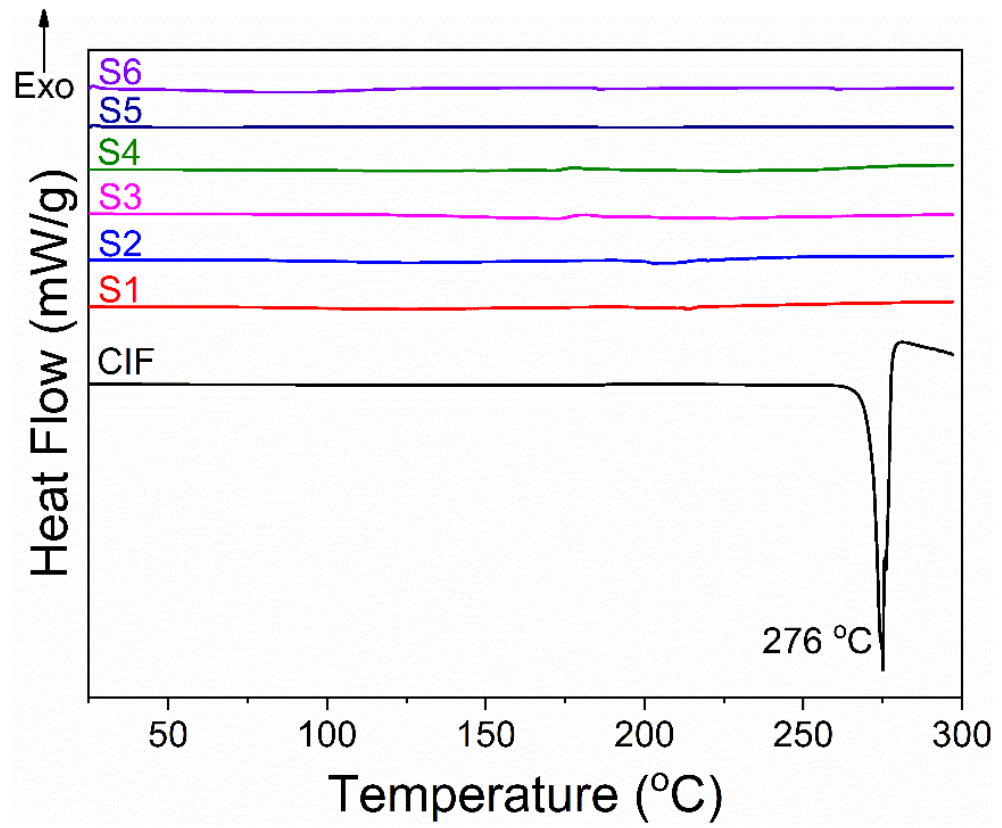

Figure 4. DSC thermograms of CIF and the fibers collected on foil, S1-S6.

\section{Infrared spectroscopy}

FITR spectra of CIF and the fiber samples collected on foil are given in Figure 5. The IR spectrum for CIF shows distinct peaks at 1588 and $1540 \mathrm{~cm}^{-1}$ from benzene ring stretching vibrations. The band at $3200 \mathrm{~cm}^{-1}$ corresponds to $\mathrm{O}-\mathrm{H}$ stretching, and $\mathrm{C}=\mathrm{O}$ stretching is present at $1612 \mathrm{~cm}^{-1}$. For the neat PVP fibers (S1), characteristic peaks from $\mathrm{C}=\mathrm{O}$ and $\mathrm{C}-\mathrm{N}$ stretching appear at 1648 and $1288 \mathrm{~cm}^{-1}$ respectively. Bands from 2980 to $2880 \mathrm{~cm}^{-1}$ result from $\mathrm{CH}_{2}$ and $\mathrm{CH}$ vibrations. In the IR spectra of the CIFloaded PVP fibers S2 and S3, the characteristic peaks of PVP are clearly visible. Some peaks shifts can also be seen. For example, the peak at $1648 \mathrm{~cm}^{-1}$ in S1 shifts to 1649 $\mathrm{cm}^{-1}$ in $\mathrm{S} 2$ and $\mathrm{S} 3$. This can be attributed to intermolecular interactions (such as $\mathrm{H}$ bonding between PVP and CIF. The presence of CIF in the fibers is clear from the appearance of additional peaks matching the pure drug between 1000 and $1250 \mathrm{~cm}^{-1}$ in $\mathrm{S} 2$ and $\mathrm{S} 3$ (cf. S1).

The S4 sample (neat EC fibers) displays characteristic peaks arising from $\mathrm{OH}$ groups (ca. $3640 \mathrm{~cm}^{-1}$ ) and C-O-C stretches $\left(1060 \mathrm{~cm}^{-1}\right)$. For the drug-loaded EC fibers (S5 and S6) peak shifts can again be seen. A band at around 1613-1614 $\mathrm{cm}^{-1}$ from the $\mathrm{C}=\mathrm{O}$ stretching of $\mathrm{CIF}$ is visible in addition to the distinct peaks of $\mathrm{EC}$, confirming the 
existence of the drug in the S5 and S6 nanofibers. Therefore, the FTIR spectra demonstrate the successful incorporation of CIF into the fibers.

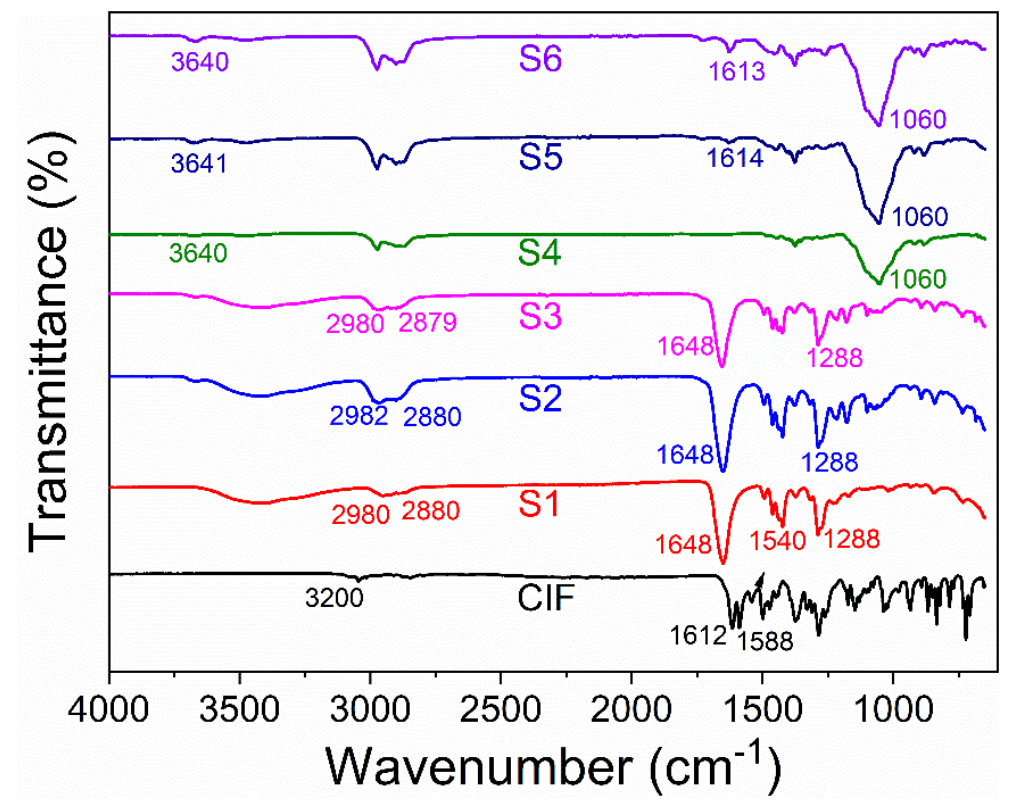

Figure 5. FTIR spectra of CIF and the fibers collected on foil.

\section{Drug release}

Drug release from the fibers collected on both foil and gauze was studied. The profiles of the CIF-loaded PVP fibers (S2, S3, S2G and S3G) are given in Figure 6. They display rapid release. For the fibers collected on foil, the $\mathrm{S} 2$ fibers $(5 \% \mathrm{w} / \mathrm{w}$ CIF) show a more rapid rate of release in the later stages of the test than the S3 fibers $(15 \% \mathrm{w} / \mathrm{w}$ CIF). After 480 min, both sets of fibers have released some $90 \%$ of their CIF loading. The fibers collected on the gauze showed similar CIF behavior, except with a greater release rate at the very start of the experiment in the case of S2G, and generally more rapid release for S3G. The f1 (difference) and f2 (similarity) factors were calculated. For $\mathrm{F} 2$ vs $\mathrm{F} 2 \mathrm{G}, \mathrm{f} 1=14$ and $\mathrm{f} 2=58$, while for $\mathrm{F} 3$ vs $\mathrm{F} 3 \mathrm{G} \mathrm{f1}=23$ and $\mathrm{f} 2=50$. The FDA considers $\mathrm{f} 2 \geq 50$ to denote similarity between two dissolution profiles, and thus both for the F2 and F3 formulation we find that the foil and gauze samples are similar on this standard. 


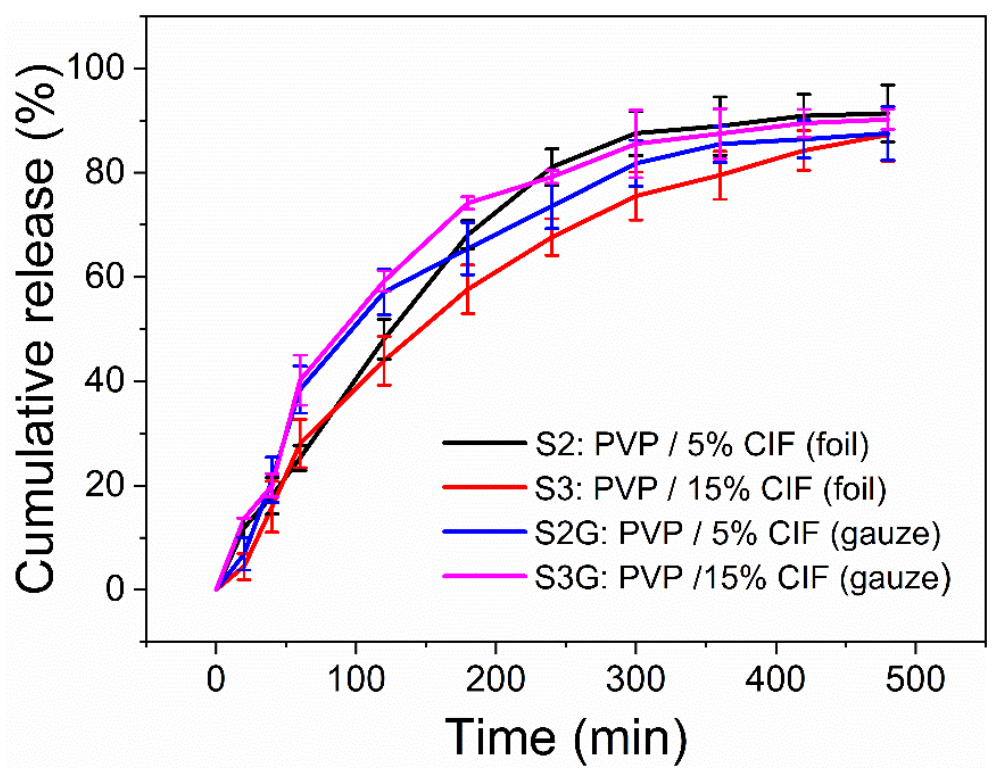

Figure 6. In vitro CIF release profiles from the PVP fibers collected on foil (S2 and S3) and gauze (S2G and $\mathrm{S} 3 \mathrm{G})$. Data are reported as mean \pm S.D. from three independent experiments.

In contrast, and as expected, the EC fibers gave much slower drug release behavior. As shown in Figure 7, an initial burst release of around $7 \%$ was seen after $4 \mathrm{~h}$. This is followed by further gradual release over more than $50 \mathrm{~h}$. By the end of the experiment (72 h), the cumulative CIF release from S5 and S6 reached $50.0 \pm 4.4 \%$ and $47.0 \pm$ $4.7 \%$, respectively. For the fibers collected on gauze, the values were slightly lower, at $46.0 \pm 4.7 \%$ (S5G) and $45.9 \pm 4.5 \%$ (S6G). When F5 is compared to F5G, we calculate $\mathrm{f} 1=21$ and $\mathrm{f} 2=64$, while for F6 vs F6G f1 $=14$ and $\mathrm{f} 2=71$. Again, we find that both the foil and gauze samples are similar based on the FDA's public standard. 


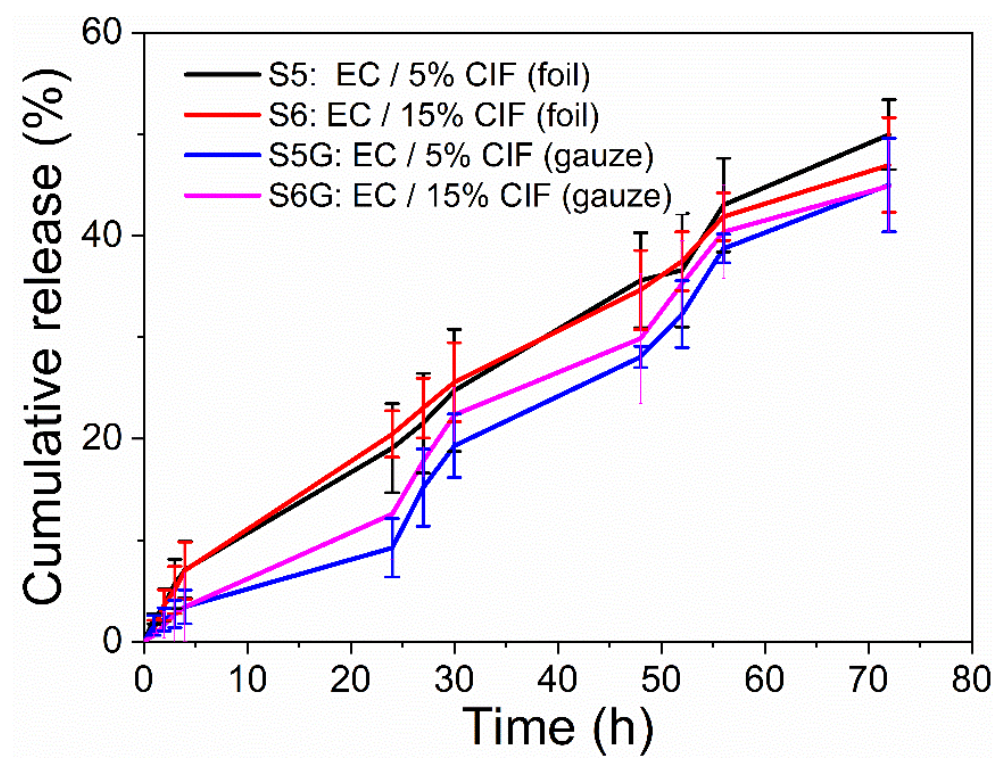

Figure 7. In vitro CIF release profiles from the EC fibers. Data are reported as mean \pm S.D. from three independent experiments.

The differences between the PVP and EC fibers release profiles result from the different properties of the two polymers. PVP is a hydrophilic polymer. Thus, the PVP fibers take up water, swell, and dissolve rapidly, thereby releasing the encapsulated CIF. For the hydrophobic EC fibers, the polymer matrix is stable and insoluble, and the fiber structure is maintained for a long time. The embedded CIF can only exit the fibers by diffusing through the matrix, a much slower process than release by dint of PVP dissolution. Both the drug-loaded PVP and EC nanofibers have potential as wound dressings. The PVP fibers could be applied to prevent infection in the early stages of the healing process, while the EC fibers could be used for the long-term treatment of chronic wounds. The extended drug release provided by the latter formulations could inhibit the growth of microorganisms around the wound area, permitting a reduction in the frequency of reapplying dressing. Since the fibers can be collected directly onto a gauze by electrospinning, multi-layered dressings with the appropriate mechanical properties can easily be prepared.

To explore the mechanism of drug release, the zero-order [42], first-order [43], and Peppas models [44] were applied. The results of the fits are summarized in Table 3, with graphical plots given in Figures S3 - S10. The data for the PVP fibers can be fitted 
reasonably well with the first-order model, consistent with the initial burst of release and subsequent tailing off observed. The zero-order release model is clearly not suitable here. However, the zero-order model provides a much closer fit to the release data from the EC fibers. The Peppas model fits well to the data for the EC fibers, but less closely to the PVP-based systems. This model takes the form $M_{t} / M_{\infty}=k t^{n}$, where $M_{t} / M_{\infty}$ denotes the extent of release, $\mathrm{k}$ is a rate constant, and $\mathrm{n}$ an exponent that provides some information on the release mechanism. The release exponents for all the fibers are seen to be larger than 0.45 but smaller than 0.89 , suggesting that CIF was released through a combined mechanism of polymer swelling and drug diffusion from the drug-loaded fibers. The $\mathrm{n}$ values are larger for the EC formulations than the PVP ones, indicating the increased importance of water ingress and swelling in determining the rate of release here. However, given the relatively poor fits noted with the PVP systems some caution is required in considering these values.

Table 3. The results of fitting kinetic models to CIF release from the fiber formulations.

\begin{tabular}{|c|c|c|c|}
\hline Formulation & Zero-order & First-order & Peppas \\
\hline S2 & $\begin{array}{c}Q=0.245 t \\
\left(\mathrm{R}^{2}=0.7915\right)\end{array}$ & $\begin{array}{c}Q=10\left(1-e^{0.006 t}\right) \\
\left(\mathrm{R}^{2}=0.9922\right)\end{array}$ & $\begin{array}{c}Q=3.418 t^{0.515} \\
\left(\mathrm{R}^{2}=0.9514\right)\end{array}$ \\
\hline S2G & $\begin{aligned} Q & =0.235 t \\
\left(\mathrm{R}^{2}\right. & =0.6963\end{aligned}$ & $\begin{array}{c}Q=10\left(1-e^{0.006 t}\right) \\
\left(\mathrm{R}^{2}=0.9804\right)\end{array}$ & $\begin{array}{c}Q=4.908 t^{0.482} \\
\left(\mathrm{R}^{2}=0.954\right)\end{array}$ \\
\hline S3 & $\begin{array}{c}Q=0.221 t \\
\left(\mathrm{R}^{2}=0.8490\right)\end{array}$ & $\begin{array}{c}Q=10\left(1-e^{0.005 t}\right) \\
\left(\mathrm{R}^{2}=0.9957\right)\end{array}$ & $\begin{array}{c}Q=2.509 t^{0.586} \\
\left(\mathrm{R}^{2}=0.9730\right)\end{array}$ \\
\hline S3G & $\begin{array}{c}Q=0.246 t \\
\left(\mathrm{R}^{2}=0.6410\right)\end{array}$ & $\begin{array}{c}Q=10\left(1-e^{0.007 t}\right) \\
\left(\mathrm{R}^{2}=0.986\right)\end{array}$ & $\begin{array}{c}Q=6.009 t^{0.455} \\
\left(\mathrm{R}^{2}=0.9505\right)\end{array}$ \\
\hline S5 & $\begin{array}{c}Q=0.736 t \\
\left(\mathrm{R}^{2}=0.9810\right)\end{array}$ & $\begin{array}{c}Q=100 \cdot\left(1-e^{0.009 t}\right) \\
\left(\mathrm{R}^{2}=0.9890\right)\end{array}$ & $\begin{array}{c}Q=1.650 t^{0.796} \\
\left(\mathrm{R}^{2}=0.9930\right)\end{array}$ \\
\hline S5G & $\begin{array}{c}Q=0.62 t \\
\left(\mathrm{R}^{2}=0.9796\right)\end{array}$ & $\begin{array}{c}Q=100 \cdot\left(1-e^{0.007 t}\right) \\
\left(\mathrm{R}^{2}=0.9645\right)\end{array}$ & $\begin{array}{c}=0.525 t^{0978} \\
\left(\mathrm{R}^{2}=0.9829\right)\end{array}$ \\
\hline S6 & $\begin{array}{c}Q=0.724 t \\
\left(\mathrm{R}^{2}=0.9699\right)\end{array}$ & $\begin{array}{c}Q=100 \cdot\left(1-e^{0.009 t}\right) \\
\left(\mathrm{R}^{2}=0.9905\right)\end{array}$ & $\begin{array}{c}Q=2.142 t^{0.725} \\
\left(\mathrm{R}^{2}=0.9968\right)\end{array}$ \\
\hline S6G & $\begin{array}{c}Q=0.658 t \\
\left(\mathrm{R}^{2}=0.9865\right)\end{array}$ & $\begin{array}{c}Q=100 \cdot\left(1-e^{0.008 t}\right) \\
\left(\mathrm{R}^{2}=0.9828\right)\end{array}$ & $\begin{array}{c}Q=0.474 t^{0.969} \\
\left(\mathrm{R}^{2}=0.9868\right)\end{array}$ \\
\hline
\end{tabular}




\section{Cell viability}

The LIVE/DEAD ${ }^{\circledR}$ cell vitality assay kit was used to assess cell viability after $24 \mathrm{~h}$ of incubation with the fibers. This assay is based on the cellular reduction of $\mathrm{C}_{12}$-resazurin to red-fluorescent $\mathrm{C}_{12}$-resorufin, indicative of metabolically active cells. It also includes SYTOX $^{\circledR}$ Green, a nucleic acid staining dye which cannot permeate through intact cell membranes. Any significant green fluorescence thus demonstrates the presence of compromised cell membranes, indicating injured or dead cells. Cell viability data are given in Figure 8. The viability of HDF cells exposed to all the fiber formulations was close to $100 \%$, and there were no significant differences between any of the groups and the untreated cells control. (one-way ANOVA; $p>0.05$ ). Thus, none of the fibers have any toxicity to HDF cells.

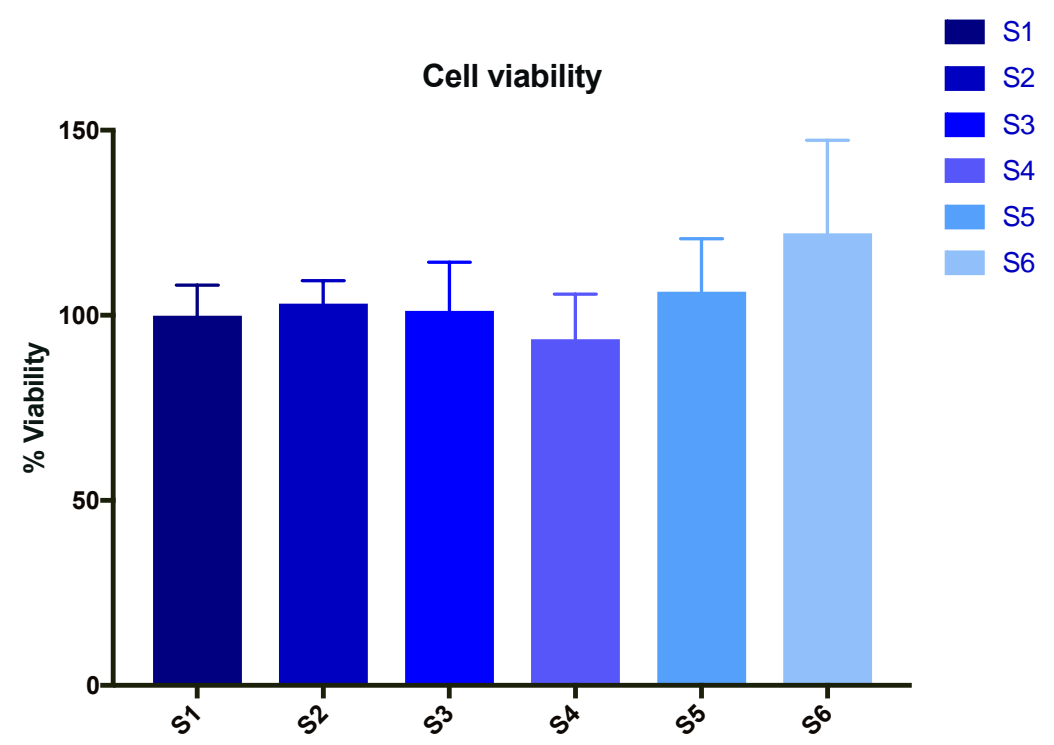

Figure 8. HDF cell viability after $24 \mathrm{~h}$ of incubation with the fiber formulations. Results are presented as mean $\pm \mathrm{SD}(\mathrm{n}=3)$.

The morphology of the HDF cells was examined using fluorescence microscopy to distinguish metabolically active and dead cells. The cells showed similar morphology to the control after being exposed to the PVP fibers (see Figure 9). In the bright field image, the fibers cannot be seen, which is because PVP is hydroscopic and will absorb water, swell and merge when immersed in the culture medium. The cells have the typical elongated morphology of fibroblasts, and clearly can adhere to and proliferate 
on the PVP fiber-coated coverslips. Considering the fluorescence images, the treated HDF cells have high red fluorescence from $\mathrm{C}_{12}$-resorufin, but there is negligible

395 fluorescence from SYTOX ${ }^{\circledR}$ Green. This indicates that the cells are metabolically active and have no membrane damage. Overall therefore, we can conclude that the HDF cells can spread and proliferate on the PVP fibers, and there is no cytotoxicity.

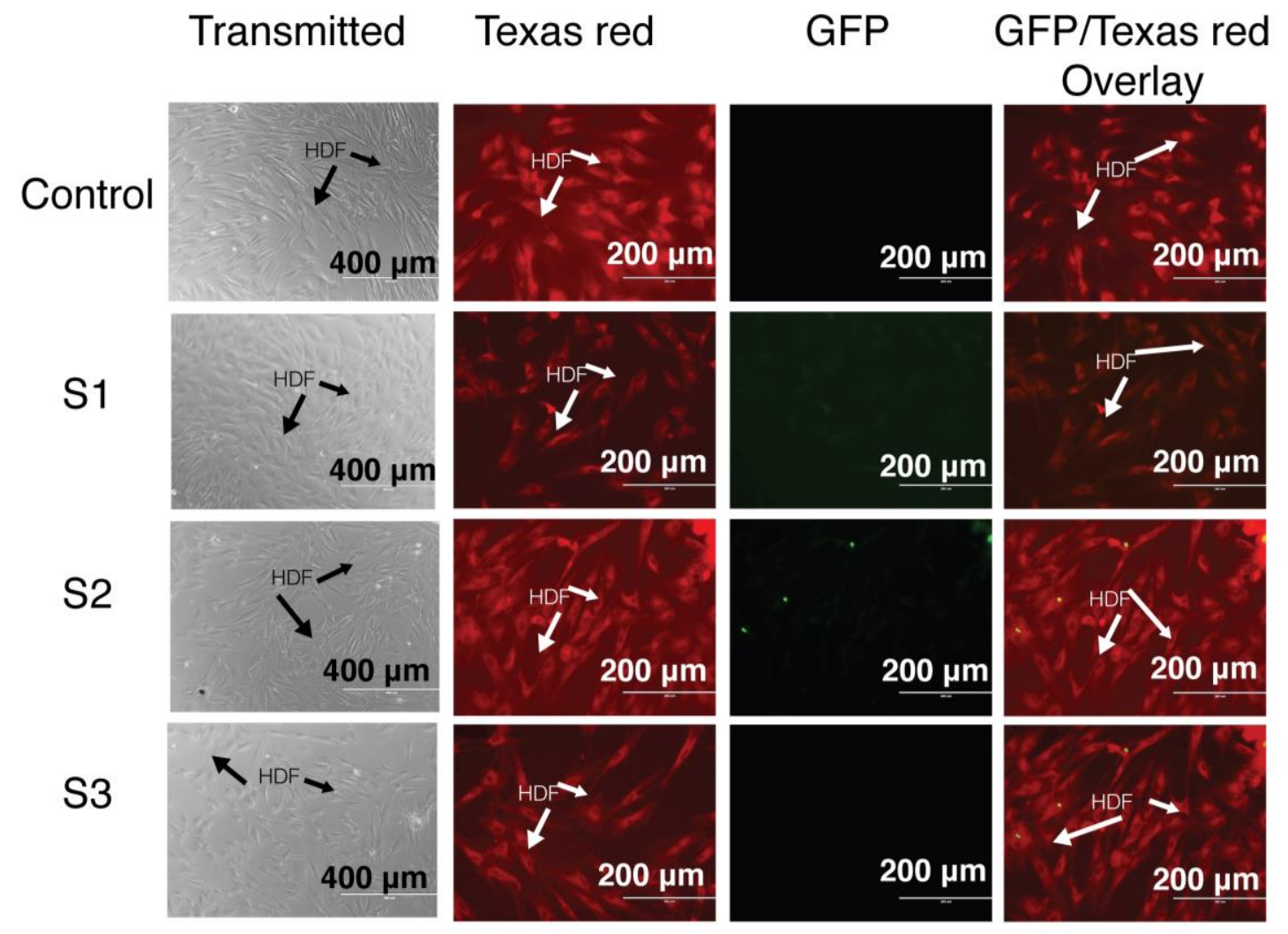

400 Figure 9. Fluorescence microscope images of HDF cells treated with $\mathrm{C}_{12}$-resaruzurin and SYTOX $^{\circledR}$ Green after 24 incubation with the PVP fiber formulations (S2-S4). Please note that the brighfield images are not necessarily from the same area of the well as the fluorescence images.

Similarly to the PVP fibers, the EC formulations led to the cells exhibiting high levels of red fluorescence, with only low very levels of green fluorescence observed (Figure 10). This again demonstrates a lack of cytotoxicity. Because the EC fibers remain intact after immersion in the cell culture medium, it can be challenging to resolve the cells in the bright field images. However, again the expected spindle morphology can be seen, and the HDF cells are distributed across the EC fibers, suggesting cell adhesion and proliferation and confirming the systems to be biocompatible and capable of supporting 
cell growth. These findings all support the potential of the fibers to be used in wound dressings.

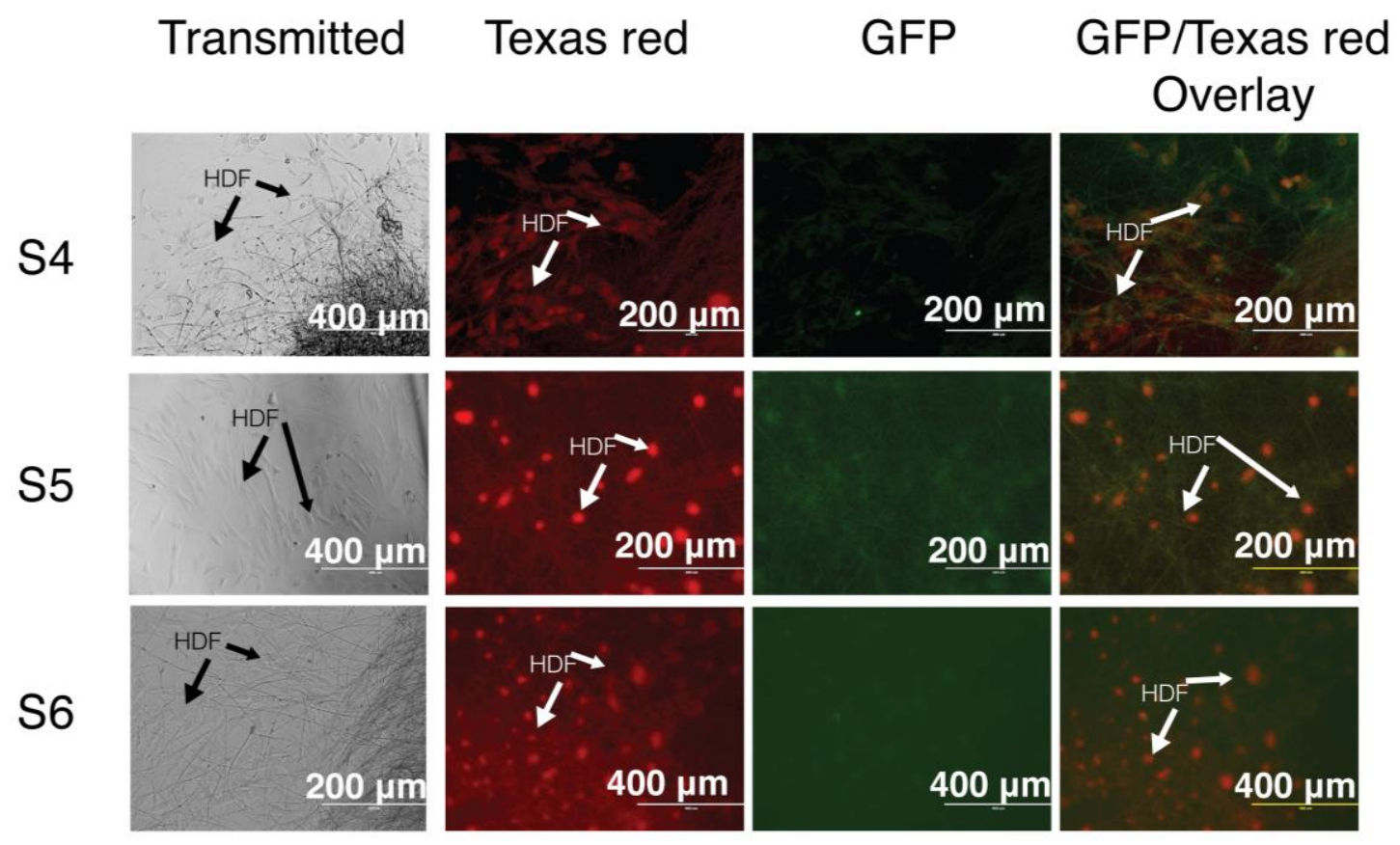

415

Figure 10. Fluorescence microscope images of HDF cells treated with $\mathrm{C}_{12}$-resaruzurin and SYTOX $^{\circledR}$ Green after 24 incubation with the EC fiber formulations (S4-S6). Please note that the brighfield images are not necessarily from the same area of the well as the fluorescence images.

\section{Antibacterial activity}

Exemplar photographs from antibacterial activity assays with the fibers collected on foil are shown in Figures 11 and 12. Images for fibers collected on the gauze can be seen in Figures S11 and S12. The inhibition zone data are given Table 4. A clear inhibition zone within and around all the CIF-loaded fibers can be seen after $24 \mathrm{~h}$ incubation at $37^{\circ} \mathrm{C}$, for both the Gram-positive and Gram-negative bacteria. However, these inhibition zones do not appear with the fibers without CIF (S1 and S4). The inhibition zones of the CIF-loaded PVP fibers (S2 and S3) for E. coli and S. aureus after $24 \mathrm{~h}$ are between $5.65-5.75 \mathrm{~cm}$, which are larger than those of the CIF-loaded EC fibers $(4.65-4.75 \mathrm{~cm})$. This is because of the greater wettability and faster drug release rates of the PVP nanofibers compared to the EC material. With both polymers however, 
effective inhibition of bacterial growth is seen. Wound dressings based on both will prevent infection by exogenous organisms, and hence the PVP and EC nanofibers loaded with CIF can potentially be applied as antibacterial wound dressing materials. The inhibition zones observed with fibers collected on gauze are identical to those when aluminium foil was employed as the collector, confirming that electrospinning can be used to directly apply a drug-eluting layer to a standard gauze with no loss of potency.

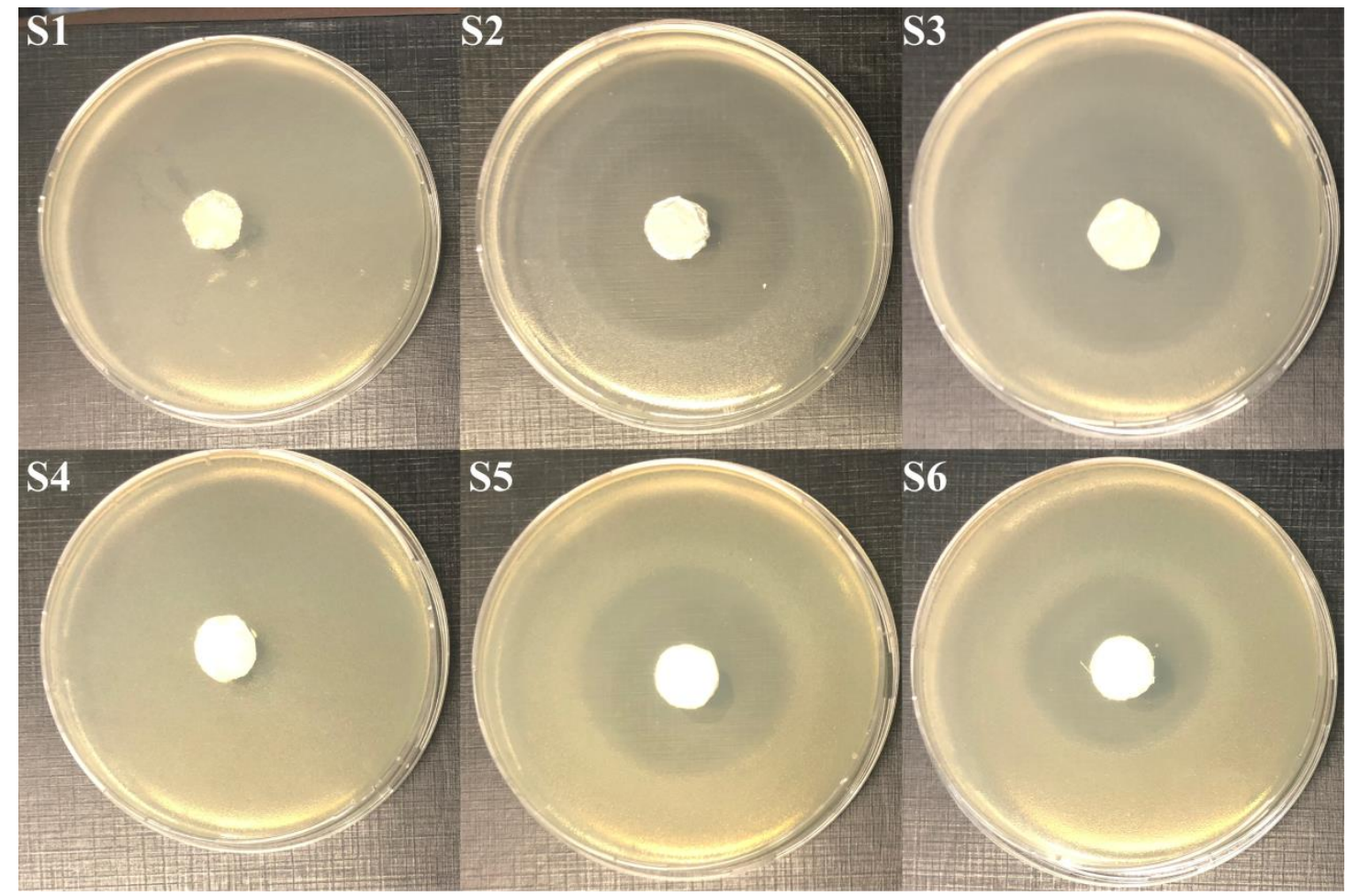

440 Figure 8. Bactericidal activity of the fibers collected on foil against $E$. coli. Representative images from the three replicate experiments are shown. 


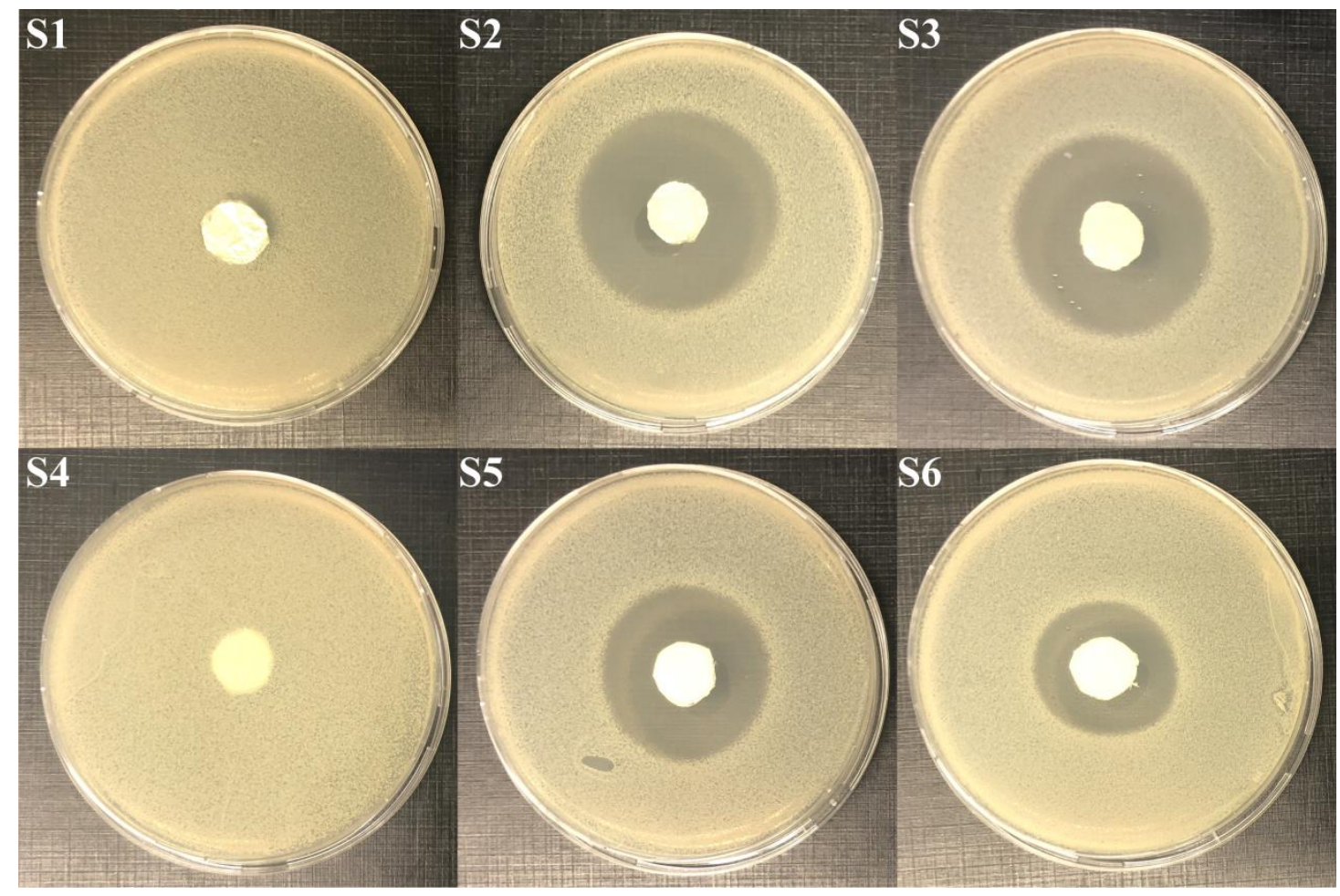

Figure 9. Bactericidal activity of the fibers collected on foil against $S$. aureus. Representative images from the three replicate experiments are shown.

Table 4. Inhibition zone diameters. Data are reported as mean \pm S.D. from three independent experiments.

\begin{tabular}{|c|c|c|c|c|}
\hline & \multicolumn{2}{|c|}{ Foil collector } & \multicolumn{2}{|c|}{ Gauze collector } \\
\hline & Sample & Inhibition zone (cm) & Sample & Inhibition zone $(\mathrm{cm})$ \\
\hline \multirow{6}{*}{$\begin{array}{l}\dot{\tilde{8}} \\
\dot{0}\end{array}$} & S1 & -- & -- & -- \\
\hline & S2 & $5.66 \pm 0.47$ & S2G & $5.69 \pm 0.50$ \\
\hline & S3 & $5.71 \pm 0.60$ & S3G & $5.62 \pm 0.67$ \\
\hline & S4 & -- & -- & -- \\
\hline & S5 & $4.72 \pm 0.23$ & S5G & $4.65 \pm 0.48$ \\
\hline & S6 & $4.69 \pm 0.39$ & S6G & $4.73 \pm 0.34$ \\
\hline \multirow{6}{*}{ 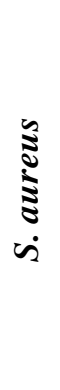 } & S1 & -- & -- & -- \\
\hline & S2 & $5.32 \pm 0.74$ & S2G & $5.25 \pm 0.71$ \\
\hline & S3 & $5.30 \pm 0.61$ & S3G & $5.26 \pm 0.72$ \\
\hline & S4 & -- & -- & -- \\
\hline & S5 & $4.33 \pm 0.82$ & S5G & $4.22 \pm 0.81$ \\
\hline & S6 & $4.29 \pm 0.77$ & S6G & $4.30 \pm 0.32$ \\
\hline
\end{tabular}




\section{Conclusions}

Nanofibers composed of ethyl cellulose (EC) or poly(vinylpyrrolidone) (PVP) and loaded with CIF were successfully fabricated via electrospinning. The fibers have regular and smooth morphologies in general, although some beads could be seen in the CIF-loaded fibers. Fibers could be collected both on a standard foil collector, or on a gauze to prepare functional fabrics. The morphological characteristics of the fibers appear largely unaffected by the collector substrate, but there is more curvature in those formed on the gauze. XRD and DSC data showed that the fibers comprise amorphous solid dispersions of CIF in a polymer matrix. The successful incorporation of CIF in the nanofibers was verified by IR spectroscopy. In vitro drug release tests were performed to simulate release from dressings into wounds. The results revealed that CIF was released rapidly from the PVP fibers, and much more slowly from the EC fibers. CIF release arises from a combination of polymer swelling and drug diffusion. CIF release from the EC fibers occurred at an almost-constant rate, and the release plots could be well-fitted with the zero-order release equation. Fibroblast cells can grow and proliferate on the fibers. The drug-loaded nanofibers are effective at preventing the proliferation of both Gram positive and Gram negative bacteria. In all the functional performance tests, the fibers collected on foil and those on gauze behave similarly. Overall, this study demonstrates that EC or PVP fibers loaded with CIF are promising as wound dressing materials, and that electrospinning can effectively be used to directly apply a functional layer to pre-formed fabrics.

\section{Acknowledgements}

The authors gratefully acknowledge the following for funding: the Royal Society International Exchanges Scheme (IE161184), the Engineering and Physical Sciences Research Council (EP/R512746/1), the UCL Global Engagement Fund, the National Science Foundation of Sri Lanka (NSF/SCH/2018/02), and the China Scholarship Council (award to Heyu Li to study at University College London). 


\section{References}

[1] Kamoun, E. A., Chen, X., Eldin, M. S. M., \& Kenawy, E. R. S. (2015). Crosslinked poly(vinyl alcohol) hydrogels for wound dressing applications: A review of remarkably blended polymers. Arabian Journal of Chemistry, 8(1), 1-14.

[2] Rezvanian, M., Amin, M. C. I. M., \& Ng, S. F. (2016). Development and physicochemical characterization of alginate composite film loaded with simvastatin as a potential wound dressing. Carbohydrate Polymers, 137, 295-304.

[3] Tran, P. L., Hamood, A. N., de Souza, A., Schultz, G., Liesenfeld, B., Mehta, D., \& Reid, T. W. (2015). A study on the ability of quaternary ammonium groups attached to a polyurethane foam wound dressing to inhibit bacterial attachment and biofilm formation. Wound Repair and Regeneration, 23(1), 74-81.

[4] Zhao, X., Wu, H., Guo, B., Dong, R., Qiu, Y., \& Ma, P. X. (2017). Antibacterial antioxidant electroactive injectable hydrogel as self-healing wound dressing with hemostasis and adhesiveness for cutaneous wound healing. Biomaterials, 122, 3447.

[5] Jin, S. G., Kim, K. S., Yousaf, A. M., Kim, D. W., Jang, S. W., Son, M. W., ... \& Choi, H. G. (2015). Mechanical properties and in vivo healing evaluation of a novel Centellaasiatica-loaded hydrocolloid wound dressing. International Journal of Pharmaceutics, 490(1-2), 240-247.

[6] Parsons, D., Meredith, K., Rowlands, V. J., Short, D., Metcalf, D. G., \& Bowler, P. G. (2016). Enhanced performance and mode of action of a novel antibiofilm Hydrofiber ${ }^{\circledR}$ wound dressing. BioMed Research International, 2016, 7616471.

[7] Zahedi, P., Rezaeian, I., Ranaei - Siadat, S. O., Jafari, S. H., \& Supaphol, P. (2010). A review on wound dressings with an emphasis on electrospun nanofibrous polymeric bandages. Polymers for Advanced Technologies, 21(2), 77-95.

[8] Ahmed, F. E., Lalia, B. S., \& Hashaikeh, R. (2015). A review on electrospinning for membrane fabrication: challenges and applications. Desalination, 356, 15-30.

[9] Brown, T. D., Dalton, P. D., \& Hutmacher, D. W. (2016). Melt electrospinning today: An opportune time for an emerging polymer process. Progress in Polymer Science, 
$56,116-166$.

510 [10] Hu, X., Liu, S., Zhou, G., Huang, Y., Xie, Z., \& Jing, X. (2014). Electrospinning of polymeric nanofibers for drug delivery applications. Journal of Controlled Release, 185, 12-21.

[11] Huang, Z. M., Zhang, Y. Z., Kotaki, M., \& Ramakrishna, S. (2003). A review on polymer nanofibers by electrospinning and their applications in nanocomposites. Composites Science and Technology, 63(15), 2223-2253.

[12] Toncheva, A., Spasova, M., Paneva, D., Manolova, N., \& Rashkov, I. (2014). Polylactide (PLA)-based electrospun fibrous materials containing ionic drugs as wound dressing materials: a review. International Journal of Polymeric Materials and Polymeric Biomaterials, 63(13), 657-671.

[13] Hassiba, A. J., El Zowalaty, M. E., Webster, T. J., Abdullah, A. M., Nasrallah, G. K., Khalil, K. A., ... \& Elzatahry, A. A. (2017). Synthesis, characterization, and antimicrobial properties of novel double layer nanocomposite electrospun fibers for wound dressing applications. International Journal of Nanomedicine, 12, 2205.

[14] Yang, X., Fan, L., Ma, L., Wang, Y., Lin, S., Yu, F., ...\& Wang, H. (2017). Green electrospun Manuka honey/silk fibroin fibrous matrices as potential wound dressing. Materials \& Design, 119, 76-84.

[15] Ali, I. H., Khalil, I. A., \& El-Sherbiny, I. M. (2016). Single-dose electrospun nanoparticles-in-nanofibers wound dressings with enhanced epithelialization, collagen deposition, and granulation properties. ACS Applied Materials \& Interfaces, 8(23), 14453-14469.

[16] Pilehvar-Soltanahmadi, Y., Dadashpour, M., Mohajeri, A., Fattahi, A., Sheervalilou, R., \& Zarghami, N. (2018). An overview on application of natural substances incorporated with electrospunn anofibrous scaffolds to development of innovative wound dressings. Mini Reviews in Medicinal Chemistry, 18(5), 414-427.

535

[17] Heydari, P., Varshosaz, J., ZargarKharazi, A., \&Karbasi, S. (2018). Preparation and evaluation of poly glycerol sebacate/poly hydroxy butyrate core - shell electrospun nanofibers with sequentially release of ciprofloxacin and simvastatin in wound dressings. Polymers for Advanced Technologies, 29(6), 1795-1803. 
[18] Tsekova, P. B., Spasova, M. G., Manolova, N. E., Markova, N. D., \& Rashkov, I. B. (2017). Electrospun curcumin-loaded cellulose acetate/polyvinylpyrrolidone fibrous materials with complex architecture and antibacterial activity. Materials Science and Engineering: C, 73, 206-214.

[19] Zhang, Y., Park, M., Kim, H. Y., El-Newehy, M., Rhee, K. Y., \& Park, S. J. (2015). Effect of $\mathrm{TiO} 2$ on photocatalytic activity of polyvinylpyrrolidone fabricated via electrospinning. Composites Part B: Engineering, 80, 355-360.

[20] Lu, H., Wang, Q., Li, G., Qiu, Y., \& Wei, Q. (2017). Electrospun water-stable zein/ethyl cellulose composite nanofiber and its drug release properties. Materials Science and Engineering: C, 74, 86-93.

[21] Park, J. Y., Kim, J. I., \& Lee, I. H. (2015). Fabrication and characterization of antimicrobial ethyl cellulose nanofibers using electrospinning techniques. Journal of Nanoscience and Nanotechnology, 15(8), 5672-5675.

[22] Hu, J., Li, H. Y., Williams, G. R., Yang, H. H., Tao, L., \& Zhu, L. M. (2016). Electrospun poly (N-isopropylacrylamide)/ethyl cellulose nanofibers as thermoresponsive drug delivery systems. Journal of Pharmaceutical Sciences, 105(3), 1104-1112.

[23] Huang, L. Y., Branford-White, C., Shen, X. X., Yu, D. G., \& Zhu, L. M. (2012). Time-engineeringed biphasic drug release by electrospun nanofiber meshes. International Journal of Pharmaceutics, 436(1-2), 88-96.

[24] Li, H., Liu, K., Sang, Q., Williams, G. R., Wu, J., Wang, H., \& Zhu, L. M. (2017). A thermosensitive drug delivery system prepared by blend electrospinning. Colloids and Surfaces B: Biointerfaces, 159, 277-283.

[25] Godakanda, V. U., Li, H. Y., Alquezar, L., Zhao, L. X., Zhu, L. M., de Silva, R., de Silva, K. M. N., \& Williams, G.R (2019). Tunable drug release from blend poly(vinyl pyrrolidone)-ethyl cellulose nanofibers. International Journal of Pharmaceutics, 562, 172-179.

[26] Wutticharoenmongkol, P., Hannirojram, P., \& Nuthong, P (2019). Gallic acidloaded electrospun cellulose acetate nanofibers as potential wound dressing materials. Polymers for Advanced Technologies, 30(4), 1135-1147. 
[27] He, F.L., Deng, X.D., Zhou, Y.Q., Zhang, T.D., Zhang, T.D., Liu, Y.L., Ye, Y.J., \& Yin, D.C. (2019). Controlled release of antibiotics from poly-epsiloncaprolactone/polyethylene glycol wound dressing fabricated by direct-writing melt electrospinning. Polymers for Advanced Technologies, 30(2), 425-434.

[28] Yazdanbakhsh, M.F., Rashidi, A., Rahimi, M.K., Khajavi, R., \& Shafaroodi, H (2018). The effect of impregnated alpha-cellulose nanofibers with ciprofloxacin hydrochloride on staphylococcus aureus in vitro and healing process of wound in rat. Regenerative Engineering and Translational Medicine 4(4), 247-256.

[29] Najafabadi, S.A.A., Shirazaki, P., Kharazi, A.Z., Varshosaz, J., Tahriri, M. \& Tayebi, L (2018). Evaluation of sustained ciprofloxacin release of biodegradable electrospun gelatin/poly(glycerol sebacate) mat membranes for wound dressing applications. Asia-Pacific Journal of Chemical Engineering, 13(6), e2255.

[30] Liu, X.L., Nielsen, L.H., Klodziliska, S.N., Nielsen, H.M., Qu, H.Y., Christensen, L.P., Rantanen, J., \& Yang, M.S (2018). Ciprofloxacin-loaded sodium alginate/poly (lactic-co-glycolic acid) electrospun fibrous mats for wound healing. European Journal of Pharmaceutics and Biopharmaceutics, 123, 42-49.

585 [31] Li, H., Williams, G.R., Wu, J. Lv, Y., Sun, X., Wu, H., \& Zhu, L.M. (2017). Thermosensitive nanofibers loaded with ciprofloxacin as antibacterial wound dressing materials. International Journal of Pharmaceutics, 517, 135-147.

[32] Khorshidi, S, \& Karkhaneh, A (2018). On-demand release of ciprofloxacin from a smart nanofiber depot with acoustic stimulus. Journal of Biosciences, 43(5), 959967.

[33] Larraneta, E., Stewart, S., Fallows, S.J., Birkhauer, L.L., McCrudden, M.T.C., Woolfson, A.D., Donnelly, R.F. (2016). A facile system to evaluate in vitro drug release from dissolving microneedle arrays. International Journal of Pharmaceutics, 497, 62-69. Y.S., Jung, C., El-Newehy, M., Kim, H.Y. (2012). Wound-dressing materials with antibacterial activity from electrospun polyurethane-dextran nanofiber mats containing ciprofloxacin HCl. Carbohydrate Polymers, 90, 1786-1793. 
[35] Chen, Y., Lu, Z., Zhou, L., Mai, Y. W., \& Huang, H. (2012). Triple-coaxial 600 electrospun amorphous carbon nanotubes with hollow graphitic carbon nanospheres for high-performance Li ion batteries. Energy \& Environmental Science, 5(7), 7898-7902.

[36] Nagy, Z. K., Balogh, A., Démuth, B., Pataki, H., Vigh, T., Szabó, B., ... \& Verreck, G. (2015). High speed electrospinning for scaled-up production of amorphous solid dispersion of itraconazole. International Journal of Pharmaceutics, 480(12), 137-142.

[37] Unnithan, A. R., Barakat, N. A., Pichiah, P. T., Gnanasekaran, G., Nirmala, R., Cha, Y. S., ... \& Kim, H. Y. (2012). Wound-dressing materials with antibacterial activity from electrospun polyurethane-dextran nanofiber mats containing ciprofloxacin HCl. Carbohydrate Polymers, 90(4), 1786-1793.

[38] Chen, G., Guo, J., Nie, J., Ma, G. (2016). Preparation, characterization, and application of PEO/HA core shell nanofibers based on electric field induced phase separation during electrospinning, Polymer, 83, 12 - 19.

[39] Li, H., Wang, M., Williams, G.R., Wu, J., Sun, X., Lv, Y., \& Zhu, L.M (2016). Electrospun gelatin nanofibers loaded with vitamins $\mathrm{A}$ and $\mathrm{E}$ as antibacterial wound dressing materials. RSC Advances, 6(55), 50267 - 50277.

[40] Deitzel, J.M., Kleinmeyer, J., Harris, D.E.A., \& Tan, N.B (2001). The effect of processing variables on the morphology of electrospun nanofibers and textiles, Polymer, 42(1), $261-272$

[41] Jia, Y.T., Gong, J., Gu, X.H., Kim, H.Y., Dong, J., Shen, X.Y. (2007). Fabrication and characterization of poly (vinyl alcohol)/chitosan blend nanofibers produced by electrospinning method, Carbohydrate Polymers, 67(3), $403-409$.

[42] Varelas, C. G., Dixon, D. G., \& Steiner, C. A. (1995). Zero-order release from biphasic polymer hydrogels. Journal of Controlled Release, 34(3), 185-192.

[43] Siepmann, J., \&Peppas, N. A. (2001). Modeling of drug release from delivery systems based on hydroxypropyl methylcellulose (HPMC). Advanced Drug Delivery Reviews, 48(2-3), 139-157.

[44] Ritger, P.L., \& Peppas, N.A (1987). A simple equation for description of solute 
release I. Fickian and non-Fickian release from non-swellable devices in the form of slabs, spheres, cylinders or discs. Journal of Controlled Release, 5(1), 23 - 36. 